\title{
EL MOMENTO PREVIO A LA VERDAD: TEORÍA Y ÉTICA DEL ENSAYO EN MARTÍN CERDA
}

\author{
THE MOMENT BEFORE THE TRUTH. THEORY AND ETHICS FROM \\ THE ESSAY ON MARTÍN CERDA
}

\author{
Felipe González Alfonso
}

Pontificia Universidad Católica de Valparaíso

Universidad de Playa Ancha. Chile

fgonzalez.alfonso@gmail.com

Ximena Figueroa Flores

Universidad Academia de Humanismo Cristiano. Chile

xfigueroa@academia.cl

\begin{abstract}
Resumen: A través de un recorrido por los fundamentos teóricos del género ensayístico planteados por Georg Lukács, Theodor Adorno, Martín Cerda e Ismael Gavilán, proponemos que en su afán científico y artístico, el ensayo querría escenificar el momento previo a la verdad, el discurrir del pensamiento anterior a las conclusiones definitivas. Teniendo como ejemplo la obra del mismo Martín Cerda y su vínculo con el difícil contexto de la dictadura, indagamos en la actualización de las características del género en la obra del ensayista chileno que, dado además el talante escéptico del ensayo, presentaría una problemática dimensión ética, debatiéndose entre el escapismo, el individualismo y la apertura hacia un espacio de libertad crítica en medio de la censura y la violencia.
\end{abstract}

Palabras clave: Teoría, ensayo, Martín Cerda, escepticismo.

Abstract: Upon focusing on the theoretical fundamentals of the essay genre as referred to by Georg Lukács, Theodor Adorno, Martin Cerda and Ismael Gavilan, we state that in its scientific and artistic objective, the essay aims at showing the moment before the actual truth, to such an extent that it behaves as the stream of thought prior to final conclusions. By focusing on Martin Cerda's works and the influence they receive from the difficult context of the Chilean dictatorship, we reflect on the innovation of the characteristics of the essay genre found in the Chilean essayist's legacy since, apart from involving the common skepticism of the essay, it presents troublesome ethical considerations. Thus, there is a triad of escapism, individualism and the opening to a space of critical liberty amidst censorship and violence.

Keywords: Theory, essay, Martin Cerda, skepticism.

Recibido: 19.01.2018. Aceptado: 17.10.2018. 


\section{El momento previo a la verdad}

$\mathrm{E}$ la epístola introductoria a su temprana colección de ensayos, El alma de las estrategias textuales más propias del género ensayístico: la ironía, la cual, dice, "consiste en que el crítico está hablando siempre de las cuestiones últimas de la vida, pero siempre también en un tono como si se tratara sólo de imágenes y de libros...” (1985: 27). Esta característica es visible, de hecho, al inicio del mismo texto, pues Lukács manifiesta, primero, la necesidad de determinar cuál es el derrotero común de sus ensayos, y luego se traslada a cuestionamientos generales sobre ese género discursivo. Lukács deja en claro, desde un comienzo, que el tema particular - sus propios ensayos- es la excusa para una reflexión mayor, y así evidencia en la práctica, sin lugar a equívocos, el tropo fundamental del género. Dice: "prefiero que no hablemos aquí de mi libro; tenemos ante nosotros una cuestión más importante y general” (1985: 16). Ya instalado en esa investigación, Lukács se preguntará, entonces, por la "forma” específica del ensayo, por su relación con el arte y con la ciencia, por su posibilidad de extraer alguna verdad de lo empírico sin recurrir a la fría sistematicidad filosófica (1985: 15). Estas preguntas le permitirán aislar los rasgos esenciales del género. El ensayo, a diferencia de la investigación científica, concluye Lukács, presenta un carácter no evolutivo: leemos ensayos, en parte, porque nos instruyen, pero los buenos ensayos no se devalúan al caducar la información, y esto porque están del lado del arte $\mathrm{y}$, por lo tanto, su valor fundamental radica no en su contenido, sino en su forma. A continuación señala el deslinde: "la ciencia nos ofrece hechos y sus conexiones, el arte almas y destinos" (Lukács, 1985: 17).

En la encrucijada entre lo general y lo particular, entre lo abstracto y lo concreto -que ejemplifica con el debate medieval entre realistas y nominalistas (1985: 20)-; entre la poiesis, con sus figuraciones e imágenes, y la filosofía, con sus concatenaciones y significados, el ensayo, le sugiere Lukács a Leo Popper, parece habitar un espacio intermedio: como la poesía, elabora figuraciones, sí, pero de la experiencia mental viva del pensador en su ejercicio de atribuir y vincular sentidos:

Hay, pues, vivencias que no podrían ser expresadas por ningún gesto y que, sin embargo, ansían expresión. Por todo lo dicho sabes a cuáles 
me refiero y de qué clase son: la intelectualidad, la conceptualidad como vivencia sentimental, como realidad inmediata, como principio espontáneo de existencia... (Lukács, 1985: 23).

El ensayo es, entonces, el arte de representar esta experiencia, de figurar el momento vital, emotivo, en que surge la inquietud intelectual y se gestan las preguntas fundamentales. Las respuestas las conseguirá (o no) quien indague hechos y proponga conexiones, y para eso están los grandes sistemas filosóficos y la ciencia. El ensayo, en cambio, intenta hacer visible el momento previo a la pregunta filosófica, y la expresión adecuada para tal vivencia no puede ser sino una que subraye, recurriendo al tropo de la ironía, querría Lukács, la insuficiencia de las herramientas conceptuales (1985: 24). Estas intentarán responder posteriormente, en el tratado o en el sistema, aquellas preguntas, y borrarán el titubeo original previo a ellas. Pero en el ámbito del ensayo, dice Lukács, "la respuesta no aporta [...] ninguna solución, como la de la ciencia o, en alturas más puras, la de la filosofía...” (1985: 23).

La verdad ensayística se comprueba en sí misma, en tanto a través del lenguaje nos reenvía al acervo de las experiencias comunes, donde cualquier lector puede sentirse identificado. O, en su defecto, nos envía a experiencias inéditas que, paradojalmente, el lector imaginará con un aire familiar ${ }^{1}$. Por esta razón, el ensayo se encuentra en un punto equidistante entre la experimentación científica, cuyas verdades lo son en un ámbito abstracto, no empírico (no es perceptible la esfericidad de la tierra ni la velocidad de la luz), y las impresiones: esas experiencias particulares, aisladas, pero susceptibles de comunicarse y generar identificación en los receptores. A este tipo de comunicación identificativa, por así llamarla, el teórico José Luis Gómez Martínez la reconoce como propia del género ensayístico, oponiéndose a la idea de un significado infinitamente diferido, de imposible referencialidad, propugnada por las teorías posmodernas, desengañadas, a su juicio, del lenguaje humano y sus ambigüedades al tener como

\footnotetext{
${ }^{1}$ Coincidentemente, en la introducción a su colección de ensayos De eso se trata, Juan Villoro propone la siguiente imagen: "El ensayista acompaña y señala con el índice: 'mira'. No hay fotografía capaz de captar la extraña consonancia entre la mano que indica un detalle y la mirada brillante de quien no lo había advertido. Un invisible resplandor une al que muestra y al que entiende. El ensayo depende de ese gesto" (2007: 10).
} 
único paradigma de intercambio real la precisión científica (1992: online). Pero sucede, añade Gómez-Martínez, que la "comunicación depositaria” (o científica) no es el único medio de conexión intersubjetiva; también existe la comunicación humanística, la cual "se construye a partir de un referente común de realidad interna y que es el ser humano mismo, y mediante el cual el autor y el mensaje se realizan en el lector" (1992: online).

De hecho, para la tradición humanística en la línea de Kant y los escritores románticos, es en la experiencia estética donde se produce la instancia más estrecha de comunicación entre los seres humanos. Comentando la influencia del pensamiento kantiano en Schiller y la de éste en José Enrique Rodó, Grínor Rojo resume la concepción estética de Kant diciendo que “[e] $\mathrm{s}$ ahí [en los sentimientos dolorosos o placenteros], donde los seres humanos nos reunimos efectivamente, donde una cierta estructura de intersubjetividad deviene al fin posible” (2011: 42). Y más adelante:

En el corral de lo estético, en la aparición de un algo que es para mí y que sin embargo no deja de ser por eso lo que es, o sea que no deja de poseer por eso una eficacia que no es la que yo mismo inscribo en él, es donde el pensamiento kantiano sublima la realidad de su impotencia epistémica (Rojo, 2011: 44).

La verdad del ensayo, podría decirse entonces, aludiendo al pensamiento romántico, es la de la común experiencia estética, la única, quizá, susceptible de ser plenamente comunicada a través del lenguaje, pues encuentra asidero en cada individuo sin la mediación del experimento científico. Esto es lo que sugiere Lukács y lo que después dirá Adorno, al apuntar, por ejemplo, que la verdad del ensayo está más cerca de las apreciaciones proustianas que de las abstracciones de la ciencia (2003: 17-18). Por esto, en nuestra opinión, no resulta pertinente la acusación de Adorno, para quien Lukács se equivocaba al arrebatar el ensayo al ámbito de la verdad y trasladarlo a los dominios del arte (2003: 13). No por adentrarse en los dominios del arte, podría rebatirse, el ensayo se aleja necesariamente de la búsqueda de la verdad. Como apunta Martín Cerda en La palabra quebrada: "Lukács, en verdad, tuvo el cuidado de precisar que el ensayo está siempre orientado hacia la verdad, pero, al mismo tiempo, le está vedado postular que cada texto suyo sea la verdad" (2005: 36). Es la orientación, creemos, la palabra clave en este fragmento: el ensayo se detiene en -y re- 
presenta, en sentido mimético- el momento en que el impulso hacia la verdad se origina y se traza hacia ella el camino, con sus meandros y aporías; todo eso que el sistema o el tratado filosófico suprimen o dejan quizá a un lado, desplazando una parte del pensamiento, de la experiencia humana y del mundo, en forma de textos preparatorios y glosas. Esto, además, según nuestra lectura, encuentra su particular actualización en las reflexiones del propio Martín Cerda, al comentar la denominación del género acuñada por Montaigne.

La elección del nombre, ensayo, cuyo étimo es Exegium, "pesar algo", no sería casual, dice en La palabra quebrada, lo exige su contexto, y conlleva un ánimo "polémico" al distanciarse de una explicación totalizante, tendiente a obtener certezas absolutas (Cerda, 2005: 19). La nueva realidad heterogénea, el comienzo de la modernidad, parece inasible para los géneros filosóficos tradicionales; requiere una forma capaz de tantear, sopesar esa realidad, y cuyas respuestas sean variables, perfectibles, múltiples, no definitivas. Esta actitud, añade Martín Cerda en el mismo libro, es "porvenirista" (2005: 19), se adelanta a una realidad imposible de inteligir a cabalidad, dada la creciente ausencia de verdades. Los modernos se sienten cada vez menos en casa, el mundo ya no les es familiar como a los antiguos y a los medievales. Así, lo que tantea Montaigne, bajo la variedad de sus temas, es la esencia misma de la modernidad, y vislumbra que, para avocarse a tal labor, hace falta un nuevo modo de conocer - titubeante, capaz de detenerse y desandar lo avanzado-y, por lo tanto, un nuevo género más flexible, proteico, reacio a las definiciones; es decir, una forma en sincronía con la realidad vertiginosa que él presagia e intenta registrar. Esta búsqueda formal, observamos, es más propia del afán literario que del filosófico; se trata de un problema artístico. Y la dificultad resulta vencida por Montaigne gracias al hallazgo del essay, esa "palabra quebrada" cuya plasticidad permite calibrar el ritmo de los tiempos.

El ensayo, entonces, en tanto poiesis, es eminentemente performativo, es decir, en él son más relevantes los gestos, las estrategias formales, que los enunciados; su construcción textual es principalmente tropológica y, como queda dicho, su tropo preferido es la ironía. Llevando esto más lejos, incluso podría decirse: lo realmente importante de la ironía ensayística no es aquello que deliberadamente oculta, "las preguntas fundamentales", sino el sentido mismo de ese encubrimiento. A este respecto, uno debería 
preguntarse, ¿por qué Lukács, en lugar de investigar directamente "la esencia del ensayo", lo hace de manera velada, mientras parece interesado en descubrir si sus ensayos transitan o no por un sendero común? ¿O por qué Adorno no realiza de manera abierta la crítica de la razón instrumental, del ego cogito y de los grandes sistemas filosóficos? Y, finalmente, ¿por qué Martín Cerda no escribe una apología de la burguesía culta y revolucionaria y luego un lamento por la dispersión democrática de esa cultura en el mundo globalizado? Esto, creemos, porque al ensayo, como se sabe, lo orienta un ánimo fundamentalmente escéptico: no le parece del todo censurable lo que critica, teme equivocarse; pero, al mismo tiempo, como repara Adorno, lo aqueja un ansia desesperada de verdad. En este sentido, como buen hijo de la modernidad, el ensayo es esencialmente contradictorio. Por lo tanto, podría decirse, no hay una confrontación real entre Lukács y Adorno (según este, el primero "arrebataría” el ensayo al ámbito de la verdad al ponerlo del lado del arte; aunque para Lukács sí está “orientado” hacia ella, como subraya Martín Cerda, pero sólo orientado, al parecer); en realidad enfatizan distintos momentos de un mismo proceso constitutivo del ensayo: Lukács, el gesto de la búsqueda; Adorno, el probable hallazgo provisorio.

Y es que, en rigor, el ensayo, dado su radical escepticismo, no confía, no puede confiar en los resultados de su propia indagación de la experiencia - vital y de las formas - impulsada, sin embargo, por el ansia de verdad. El escéptico intuye algo invariable tras el vértigo de lo sensible, pero no encuentra un modo para establecer si la apariencia, tal como se presenta a nuestros sentidos y a nuestro pensamiento, nos engaña o nos franquea la vía del saber. Nada cierto, por lo tanto, puede afirmarse de la realidad, pues, como pensaba Pirrón, filósofo griego del siglo IV antes de Cristo, fundador del escepticismo, "[s]i la naturaleza real de las cosas no puede ser conocida ni por los sentidos ni por la razón, entonces no hay nada que sirva de referencia para contrastar la verdad o falsedad de afirmaciones acerca de aquella" (Long, 1977: 87). Por este motivo, el ensayista tantea y no se detiene en sus hallazgos; cuando algo le parece cierto de inmediato recuerda la posibilidad del engaño. No puedo deslindar verdad y mentira, se dirá, pero puedo evadir la trampa y, quizá, acceder a la verdad. ¿Cómo?, examinando una variedad de respuestas sin detenerme en ninguna dema- 
siado tiempo. Sólo procediendo así el ensayista podrá decirse a sí mismo después, primero: que no ha sido burlado y; segundo: que quizá alguna vez — no sabe cuándo precisamente- tocó la verdad, pues tocó casi todos los puntos de vista.

Sólo en este sentido paradójico el ensayo buscaría la verdad, pensamos, y gracias al "método" del tanteo, sugiere Adorno, puede escapar a la trampa más común a esa búsqueda, la ideología, entendida en su sentido tradicional de "falsa consciencia". Los caminos unívocos del pensamiento cartesiano, en cambio, se entregan a ella y la sirven sin darse cuenta. En última instancia, si algo denuncia Adorno es el trasunto ideológico de la filosofía académica positivista, que deplora el ensayo porque en verdad deplora la libertad del pensamiento crítico: "El esfuerzo del sujeto por penetrar lo que como objetividad se oculta tras la fachada es estigmatizado como ocioso: por miedo a la negatividad en general" (Adorno, 2003: 12). Porque el ensayista es crítico y escéptico resulta peligroso para los presupuestos científicos y metafísicos, que han ignorado largamente las trampas insalvables del lenguaje, por el contrario siempre presentes para el ensayista gracias a su nacimiento moderno, cuya impronta se percibe en su conciencia radical frente a los espejismos del pensamiento y la escritura, sus propios elementos estructurantes:

La fácil flexibilidad del curso de los pensamientos del ensayista le obliga a una mayor intensidad que la del pensamiento discursivo, pues el ensayo no procede, como éste, ciega y automáticamente, sino que a cada instante tiene que reflexionar sobre sí mismo (Adorno, 2003: 33).

A la luz de esta característica se deberían sopesar los reproches dirigidos al género ensayístico, que así develan todo su talante mistificador. Sobre todo la hostilidad contra el pensamiento dinámico y autorreflexivo, contrario a la engañosa espontaneidad que, lejos de ser la vía más directa hacia lo particular -y por lo tanto hacía una información distinta y posiblemente contraria a la del sentido común-, es, por el contrario, el camino seguro hacia ese lugar del sujeto donde el sentido común (la ideología) se encuentra afincada. 


\section{La ética del escepticismo en la ensayística de Martín Cerda}

Al comienzo de Escritorio, segundo libro de Martín Cerda, publicado en 1987, el ensayista reconoce adeudarle a Ortega y Gasset, según dice, "el proyecto de vida que he intentado llevar adelante $y$, por consiguiente, ser el que ahora soy" (2005: 160). Tras esta confesión, Martín Cerda no se detiene a explicar cuál es exactamente ese proyecto de vida basado en Ortega; sin embargo, la confesión ilumina el sentido de algunas coincidencias significativas entre los datos biográficos con que se ha configurado al autor implícito tanto de Escritorio como de La palabra quebrada - primer libro de Martín Cerda, publicado en 1982-, y ciertos datos correspondientes a las figuras autorales de Francis Bacon y Montaigne.

Un poco más adelante del fragmento citado y como muy pocas veces en sus dos obras, Martín Cerda nos pone al tanto de la relación entre su escritura y la contingencia política. Comenta:

Cuando en noviembre de 1973, después de pensarlo y repensarlo repetidas veces, decidí continuar mi colaboración en Las Últimas Noticias, lo hice echando mano al material acumulado por ese largo trabajo de escritorio para fijar expresamente una distancia con todo aquello que comenzaba a ocurrir en el país (2005: 162).

Aquí es posible apreciar cómo el autor, recurriendo a elementos tradicionales del género ensayístico, según Gómez Martínez, es decir, la confesión y la alusión contingente (1992: online), selecciona un aspecto específico de su biografía para entroncar al autor implícito de sus ensayos en esa larga genealogía fundada por Montaigne y Bacon: la de la figura propiamente escéptica del ensayista. En este sentido, el proyecto de vida asumido por el Martín Cerda implícito, considerando su reacción frente al advenimiento de la dictadura militar chilena, parece debérsela mucho más a estos dos autores que a Ortega.

En el fragmento "El sieur de Montaigne" de La palabra quebrada, por ejemplo, el autor francés no sólo representa al ensayista por antonomasia, en cuanto tipo intelectual, sino además, es quien entrega las pautas fundamentales del modus vivendi de esa figura. Martín Cerda enfatiza que Montaigne pudo desarrollar en sus ensayos un ánimo tolerante y mesurado, confiado en la razón, sólo gracias a su renuncia a una vida pública 
agitada por el fanatismo de las luchas religiosas (2005: 40-42). Frente a la presión de escoger entre opciones extremas, contradictorias y sangrientamente enfrentadas, Montaigne decide refugiarse en la biblioteca de su castillo a redactar los Essais. Para Martín Cerda esto supone, agrega en el mismo libro, "un admirable gesto disidente" (2005: 42), pues de lo que Montaigne huye es de la imposibilidad de mantener una posición crítica, dada la polarización ideológica. Como es evidente, se trata del mismo gesto de Martín Cerda tras el golpe militar; sustentado además en la "política de la neutralidad” de Francis Bacon. Éste, aludiendo a las luchas civiles de la república romana y a las modernas de las ligas francesas, dice, en palabras de Martín Cerda en Escritorio, que:

[e]n estas situaciones extremas, el hombre discreto - al que Bacon llama, asimismo, superior- debe, a diferencia del inferior, que adhiere estrepitosamente a la facción triunfante en cada instante, mantenerse neutral o indiferente y, en el peor de los casos, adherir moderadamente a la facción "que es más tolerable que otra" (2005: 195).

A este respecto, Martín Cerda cita en el mismo libro a Roland Barthes, para quien, en esas circunstancias, hasta la verdad se desfigura teatralmente (2005: 212-213) y, por lo tanto, el ensayista chileno puede decir a continuación que la pasión política exalta o denigra al intelectual (2005: 213). Por esta razón, agrega algunas páginas más adelante, “[e]n tales emergencias, sólo cabe tomar distancia y mirar fríamente cada suceso, acto, palabra o gesto..." (Cerda 2005: 221). Las consecuencias para el ensayista que no toma distancia, sugiere Martín Cerda, pueden llegar incluso a comprometer su integridad física: Rivarol se ve "enredado" en una peligrosa coyuntura política, nos dice (2005: 212), y Cicerón, especie de Sócrates ensayista, termina muerto por su participación política (2005: 207).

La toma de distancia parece razonable en el caso comúnmente aludido por Montaigne y Bacon de las guerras religiosas, y también en toda circunstancia de riesgo vital; sin embargo, en el contexto de la dictadura chilena no el distanciamiento, pero sí el posicionamiento de Martín Cerda, pensamos, bordea la más consciente evasión, pues se trató de unas circunstancias bien distintas a los conflictos europeos: un proceso democrático que, si bien es cierto, fue perdiendo credibilidad, no se impuso mediante el fanatismo o la violencia y, en cambio, sí terminó violentamente interrumpido sin po- 
sibilidad de réplica ${ }^{2}$. Además, las afirmaciones de Martín Cerda, nos parece, dejan ver unos presupuestos erróneos: la identificación necesaria entre toma de posición y fanatismo. No es preciso ir demasiado lejos para buscar ejemplos donde esto no ocurre: nos referimos a las figuras ya aludidas aquí de Lukács y Adorno, quienes desmienten con elocuencia tal identificación, según lo ya apuntado.

Sin embargo, podría considerarse que la aparente ambigüedad política del autor implícito de Martín Cerda, devela más bien la filiación escéptica del ensayo en general, y menos esta filiación que la debilidad ética propia del escepticismo, arraigado en el género desde sus orígenes. Hablamos de "debilidad ética" en tanto tal actitud filosófica teme escoger entre dos opciones contradictorias u opuestas, pues se asume incapaz de establecer de qué lado está el error y de qué lado la verdad, y por renunciar a todo engaño renuncia también a todo atisbo de certeza. En efecto, según el filósofo peripatético Aristocles de Mesene, el fundador de la escuela, Pirrón:

declaraba que las cosas eran igualmente indiscernibles, inconmensurables e indeterminables. Por esta razón, ni nuestras percepciones ni nuestros incisos son verdaderos ni falsos. Por ello, pues, no debemos fiar de ellos, sino evitar los juicios, sin inclinarnos ni de un lado ni de otro, inflexibles... (Long, 1977: 89).

Esto último explica la actitud necesariamente dinámica del escepticismo y su actualización ensayística. El problema es que la permanente agitación del agua para evitar su estancamiento termina generando una posi-

${ }^{2}$ Para complejizar este demasiado somero trasfondo histórico, citamos al historiador Rafael Sagredo Baeza, quien dibuja el panorama social de la época señalando la disconformidad incluso de los adherentes ante la lentitud de las reformas de la UP, pero también la predisposición al quiebre democrático (y, por lo tanto, a la violencia) de las capas medias y los sectores privilegiados apenas Allende había asumido, cuando ya no era un misterio el talante social de su programa: "Para la izquierda [la Unidad Popular], se trataba solo de una democracia formal, que no era tal en la práctica, puesto que si bien existían derechos políticos para la gran mayoría de la población, en materia económica y social subsistían grandes y graves desigualdades. Para la clase media, las reivindicaciones de los sectores populares, materializadas en el programa de la UP, significaban una amenaza, frente a la cual muchos estuvieron dispuestos a sacrificar la democracia si con ello frenaban las aspiraciones populares. Finalmente, un sector importante de la derecha y los sectores más acomodados, desde el momento mismo en que Allende llegó al poder, estuvo dispuesta a renunciar a la democracia con tal de mantener su situación y privilegios” (250). 
ción ética también demasiado inestable. Pero hay algo más: la suspensión del juicio es el resultado de una búsqueda fundamentalmente individual: "El segundo rasgo del pirronismo, que señala su carácter contemporáneo, es el fin ético, la liberación de la inquietud", y, consecuentemente, otros datos consignan que Pirrón "simpatizaba con la prédica cínica a favor de una vida sencilla, apartada de los asuntos públicos” (Long, 1977: 85). Lo cual ilumina la conjunción entre ensayo y escepticismo en el marco de la modernidad, caracterizada por el giro antropológico. De hecho, como explica Gómez Martínez, el género no se concibe en la Edad Media o la Antigüedad, aunque ahí encuentre sus precedentes. Bacon, polemizando con Montaigne, dice que la palabra es nueva (essai), pero el "contenido" antiguo, rastreable en Platón, Séneca, Marco Aurelio o Plutarco. No obstante, a propósito de estos autores, Gómez Martínez apunta lo siguiente:

Sus obras, sin embargo, están todavía lejos de formar verdaderos ensayos, en el sentido que actualmente damos a la palabra. Hay que esperar a las tendencias humanísticas del Renacimiento en su proceso de descubrir al individuo, ya que el carácter subjetivista y la proyección constante del ser del escritor en sus ensayos no es concebible en la época medieval (1992: online).

En síntesis, podemos decir, aunque las teorizaciones por lo general no lo reconozcan: el ensayo posee un sustento filosófico, un posicionamiento implícito - aunque sea el de no posicionarse - que, según lo rasgos descritos (aislamiento, escepticismo e individualismo), evidencia una profunda debilidad en su aspecto ético. Un ejemplo concreto de esto en los escritos de Martín Cerda es su fascinación por la "literatura nazi” y ciertos escritores de filiación fascista como, en La palabra quebrada, Ernst Jünger (2005: 140-146). Desde la perceptiva escéptica, esta filiación no podría dejar de tener algo bueno, y el problema es que, paradójicamente, esto decanta en una visión polarizada de la Segunda Guerra Mundial en los escritos de Martín Cerda: la invisibilización del holocausto judío y el énfasis en las atrocidades del lado socialista.

Sin embargo, es pertinente establecer gradaciones en cuanto al escepticismo del ensayo dependiendo del autor. Martín Cerda, creemos, se encuentra en una tendencia más marcadamente escéptica que la de Lukács y Adorno, por ejemplo. Y por tal razón, a diferencia de estos últimos, descree 
de modo absoluto en las posibilidades cognitivas del sujeto y, en consecuencia, no ofrece la menor confianza a los proyectos colectivos. En la ensayística de Martín Cerda lo anterior se percibe en su afinidad con las ideas elitistas de Ortega; ambos miran con desdén, según se lee en Escritorio, a "la tribu frenética que hoy amenaza, destemplada e impunemente, con arrastrar a nuestro país al infierno de sus más secretas pesadillas" (2005: 235-236). Se percibe una tensión entre dos modernidades: una de tradición crítica, ilustrada, y la otra anquilosada, fanática, mentalmente perezosa. Martín Cerda lamenta la disolución masiva o democrática de la cultura burguesa aristocratizante, porque eso conlleva la muerte del espíritu crítico intrínseco a tal cultura. Por otro lado, deplora el lado conservador, "pequeñoburgués", cómodo, estancado de la burguesía (2005: 214), representado en la figura del fanático emergente en la crisis de sus creencias (2005: 218) y del "intelectual comprometido" (2005: 220). Enunciados como estos son consecuentes con la resignificación individualista del escepticismo por parte del ensayo en el contexto moderno, o al menos con cierto tipo de ensayística como la de Martín Cerda, que extrema su lucha contra la inquietud y se repliega hacia una subjetividad apartada de los asuntos públicos.

Desde la quinta región, Ismael Gavilán ha reflexionado con finos matices sobre el problemático aspecto ético de la ensayística y la figura de Martín Cerda. Siguiendo a éste último, recalca la importancia incluso social del ensayista en tiempos difíciles, al menos si su quehacer "no se vuelve [...] una especulación de erudita sofisticación, ni tampoco un artilugio escapista. [Y] Más bien se transforma en una experiencia de naufragio, en un intento por entender la disolución del sentido, en su poética" (Gavilán 2015: 54). Lejos del "artilugio escapista", el escritorio de Martín Cerda, puntualiza Gavilán, se transforma en un espacio privado de resistencia para el pensamiento crítico y en un espacio de conservación para la unidad y el orden perdidos en medio de la fragmentación dictatorial; en un lugar simbólico que resguarda la reflexión mientras transcurre el tiempo de penuria (2015: 44). Pero Ismael Gavilán también repara en el riesgo ético del afán ensayístico de Martín Cerda problematizado aquí: su crítica al pensamiento de la unidad, al pensamiento totalitario, colinda con una generalización en que toda unidad se presenta como eminentemente desastrosa, o bien con una 
tenebrosa especie de apología de la desintegración (Gavilán 2015: 57). Y justamente, esto se produce, pensamos, siguiendo a Gavilán, por la tensión anidada en el origen del género, ya señalado por Lukács: en el hecho de que el ensayo, a la vez, como "la ciencia nos ofrece hechos y sus conexiones", y como "el arte almas y destinos" (Lukács, 1985: 17); lo cual se lleva al extremo en la escritura del ensayista chileno, pues, en palabras de Gavilán, "la escritura fragmentada de Martín Cerda es - quizá paradójicamente- el tiempo, el lugar de la imposible conjunción, entre palabra crítica, palabra discursiva y relato" (2015: 58).

La problemática del ensayo y, particularmente, en la escritura de Martín Cerda, radica en un hecho quizá indisoluble; en su esfuerzo por presentarnos sobre todo - para tomar las palabras de Lukács- almas y destinos, y solo en segundo lugar hechos y conexiones. Y es que poner en escena, hacer mimesis de una emoción o un asombro en la escritura para denunciar o incluso para consolar; más en específico, re-presentar en perspectiva aquello de lo que alguien es víctima para hacerlo visible, a menudo es el gesto (incluso inconsciente) de los agresores para inocular el miedo, detener la acción y segar la utopía en el sentido de un pensamiento "porvenirista”, en palabras del propio Martín Cerda, ese pensamiento establecido en la base histórica del ensayo.

El equilibrio precario de la ensayística de Martín Cerda, situada en dictadura, Ismael Gavilán lo entrevé con iluminadora precisión: se trata, por así decir, de un Ulises debatiéndose entre la Caribdis de cierta "variación de una experiencia escatológica", y una Escila de "la hipoteca de su propia defensa utópica” (2015: 57). En nuestra opinión, entre ambas destrucciones, la seducción de la ruina y el turbio desencanto, la de Martín Cerda es una escritura ubicada más hacia este último lado, es decir, hacia el lado del desencanto, del repliegue melancólico. Pero también hay que dar cabida a la siguiente posibilidad: la escenificación de estos afectos depresores por parte del ensayista quizá busque con deliberación ciertos efectos libertarios: bien puede ser la forma de un develamiento y de una reprobación implícita de determinado estado de cosas que se re-presenta opresivamente inalterable solo para incitar a otros a cambiarlo ahí afuera, en el mundo de los hechos. 


\section{Referencias}

Adorno, Theodor. (2003). "El ensayo como forma”. Notas sobre literatura. Obras completas II. Madrid: Akal.

Cerda, Martín. (2005). La palabra quebrada (Ensayo sobre el ensayo). Escritorio. Santiago: Tajamar.

Gavilán, Ismael. (2015). Martín Cerda. Fragmentos de un mapa escritural. Valparaíso: Ediciones Inubicalistas.

Gómez-Martínez, José Luis. (1992). Teoría del ensayo. México D.F: UNAM. Edición electrónica: http://www.ensayistas.org/critica/ensayo/gomez/indice.htm

Long, Anthony. (1977). "El escepticismo”. La filosofía helenística. Estoicos, epicúreos, escépticos. Madrid: Alianza.

Lukács, Georg. (1985). "Sobre la esencia y forma del ensayo (Carta a Leo Popper)”. El alma y las formas. México D.F: Grijalbo.

Rojo, Grínor. (2011). “1900: Rodó a pesar de todo”. Clásicos latinoamericanos. Para una relectura del canon. Volumen II - El Siglo XX. Santiago: LOM.

Sagredo Baeza, Rafael. (2014). "El quiebre institucional”. Historia mínima de Chile. Madrid: Turner Publicaciones/El Colegio de México.

Villoro, Juan. (2007). "Prólogo". De eso se trata. Ensayos literarios. Santiago: Ediciones Universidad Diego Portales. 